\title{
Preservação Dos Contratos De Aprendizagem Profissional Em Tempos De Pandemia De Covid-19
}

\author{
Emerson Victor Hugo Costa de Sá *
}

Universidade Federal do Pará, Programa de Pós-Graduação em Direito, Belém-PA, Brasil.

iD https://orcid.org/000o-0002-0367-3505

\author{
Anderson Lincoln Vital da Silva ** \\ Universidade Federal do Amazonas, Faculdade de Direito, Manaus-AM, Brasil. \\ iD https://orcid.org/0000-0002-2903-8526 \\ Valena Jacob Chaves Mesquita \\ Universidade Federal do Pará, Programa de Pós-Graduação em Direito, Belém-PA, Brasil.
}

iD https://orcid.org/0000-0003-4955-1949

Resumo: O artigo analisa as estratégias de manutenção dos contratos de aprendizagem profissional em tempos de pandemia da COVID-19. Principal política pública voltada ao primeiro emprego, o instituto propicia oportunidades de formação técnico-profissional metódica para adolescentes e jovens, além de consistir em estratégia de erradicação do trabalho infantil. O cenário de crise de saúde pública, resultante do novo Coronavírus, gerou o reconhecimento do estado de calamidade pública em março de 2020, o que acarretou instabilidade nas relações jurídicas e a necessidade de adaptação normativa. Nesse contexto, analisa-se a aplicabilidade dos diplomas legais instituídos durante a crise sanitária decorrente da COVID-19, com especial ênfase na análise hermenêutica da Medida Provisória 927, cujos efeitos cessaram com a sua caducidade, e da Lei n. 14.020, de 6 de julho de 2020, fruto da conversão da Medida Provisória n. 936, notadamente quanto à preservação do trabalho do adolescente diante dessa nova realidade, por meio da aprendizagem e da qualificação profissionais em tempos de pandemia. A pesquisa utiliza o método de abordagem indutivo e apresenta-se como exploratória quanto aos objetivos, de natureza qualitativa e com base nos procedimentos bibliográfico e documental. Conclui-se que os contratos de aprendizagem se ajustaram para viabilizar a continuidade, mas há necessidade de marcos regulatórios mais precisos e atentos às especificidades do instituto, especialmente quanto ao público adolescente e o socialmente vulnerável.

Palavras-chave: COVID-19. Aprendizagem profissional. Política pública.

* Doutorando em Direito na Universidade Federal do Pará - UFPA. Auditor-Fiscal do Trabalho. E-mail: emersonvictor.sa@gmail.com

** Doutorando em Educação pela Universidade Luterana do Brasil - ULBRA. Professor Assistente da UFAM. E-mail: andersonlincoln.adv@gmail.com valena_jacob@yahoo.com.br

*** Doutora em Direito pela UFPA. Professora adjunta da Universidade Federal do Pará. Professora do Programa de Pós-Graduação em Direito. E-mail: valena jacob@yahoo.com.br

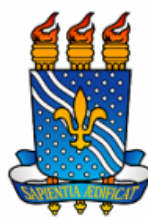

UNIVERSIDADE FEDERAL DA PARAÍBA

Programa de Pós-Graduação em Ciências Jurídicas

DOI: https://doi.org/10.22478/ufpb.1678-2593.2021v20n43.53789 


\title{
Preservação Dos Contratos De Aprendizagem Profissional Em Tempos De Pandemia De Covid- 19
}

\author{
Emerson Victor Hugo Costa de Sá
}

\author{
Anderson Lincoln Vital da Silva
}

Valena Jacob Chaves Mesquita

\section{INTRODUÇÃO}

O estudo objetiva analisar as estratégias de manutenção dos contratos de aprendizagem profissional em tempos da pandemia resultante da COVID-19. Esse instituto configura-se como instrumento de efetividade do direito fundamental à profissionalização do adolescente e do jovem, além de consistir em política pública associada à erradicação da exploração do trabalho infantil e ao primeiro acesso no mercado de trabalho formal.

Os desafios surgidos a partir do advento e da propagação do vírus em nível global exigem adaptações nos mais diversos segmentos sociais, e o Direito precisa de estratégias de regulação quanto à aplicabilidade das normas jurídicas, especialmente no contexto laboral, imediatamente atingido pelas mudanças ocasionadas nas relações de trabalho. No enfoque específico dos contratos de aprendizagem, a interpretação e a aplicação do ordenamento jurídico devem considerar a finalidade de viabilizar o ingresso e permanência do adolescente e jovem no emprego, em caráter de formação com tarefas de complexidade progressiva.

A proposta converge para a emergência de novos marcos regulatórios de adaptação do Direito diante do ambiente de crise 
instalado. Desse modo, realiza-se a abordagem crítica dos instrumentos normativos editados em 2020 e relacionados à seara trabalhista, com especial ênfase na análise hermenêutica da Medida Provisória 927, cujos efeitos cessaram com a sua caducidade, e da Lei n. 14.020, de 6 de julho de 2020, decorrente da conversão da Medida Provisória n. 936 (BRASIL, 2020c), notadamente quanto à preservação do trabalho do adolescente diante dessa nova realidade, por meio da aprendizagem e da qualificação profissionais em tempos de pandemia. Ademais, dentro de uma acepção propositiva, consideram-se na análise as orientações e decisões referentes ao programa de aprendizagem em face do cenário pandêmico, oriundas dos órgãos relacionados à temática - Inspeção do Trabalho, o Ministério Público do Trabalho e a Justiça Laboral.

A partir do direito fundamental à profissionalização, desenvolve-se o conteúdo jurídico do contrato de aprendizagem profissional, mediante a contextualização, o desenvolvimento conceitual e a exposição da finalidade e das principais características, como instrumento viabilizador do acesso dos adolescentes e jovens à cidadania e ao trabalho digno, especialmente quando em situação de vulnerabilidade e risco social.

Com efeito, a aprendizagem destina-se ao público com idade entre 14 e 24 anos, limite que não se aplica às pessoas com deficiência, conforme previsto no artigo 428 da Consolidação das Leis do Trabalho - CLT (BRASIL, 1943). Trata-se de alternativa ao afastamento de adolescentes do trabalho proibido, que viabiliza o acesso e a primeira experiência formal no mercado de trabalho e concretiza o direito fundamental à profissionalização, nos moldes do artigo 227 da Constituição da República Federativa do Brasil - CRFB (BRASIL, 1988).

Há convergência entre a faixa etária em que há maior concentração do trabalho infantil proibido (14 a 17 anos) e o público adolescente abrangido pela aprendizagem com prioridade absoluta, prevista no artigo 53 do Decreto 9.579 (BRASIL, 2018a), e 40\% dos 
adolescentes e jovens na faixa de 14 a 24 anos de idade estão em situação de desemprego (CAVALLINI e SILVEIRA, 2019).

Logo, a política de estímulo à aprendizagem encontra-se alinhada ao objetivo constitucional de erradicação do trabalho infantil, da pobreza e da marginalização, e a reserva de vagas observa o caráter de redução das desigualdades sociais e regionais, e vincula-se ao fim social da livre iniciativa, do trabalho e da propriedade, e à busca do pleno emprego, tal como orientam os artigos $1^{\circ}, \mathrm{IV}, 3^{\circ}$, IV, e 170, VIII, da CRFB (BRASIL, 1988).

O estudo justifica-se diante do cenário nebuloso que envolve as possíveis deturpações das normas e diretrizes garantidoras do acesso à profissionalização, compreensão que reforça a vocação do Direito para além da resolução de conflitos, alcançando aspectos de eficácia social e o papel transformador indispensável à evolução da ciência jurídica. Logo, resta patente a urgência e a relevância da avaliação das alternativas e estratégias normativas de implementação do contrato de aprendizagem em tempos de pandemia, para a mitigação dos efeitos negativos resultantes da eventual ausência de atenção quanto ao problema.

Os desafios do cientista jurídico não se limitam à interpretação e aplicação da norma deslocada do contexto social. Pelo contrário, mostra-se importante a análise crítica a respeito da efetividade do complexo normativo. Para além da enunciação de direitos e do enclausuramento na dogmática jurídica, compete ao pesquisador da área avaliar os efeitos concretos decorrentes da norma, seja para confirmar o acerto do conteúdo, seja para indicar ajustes na criação, interpretação ou aplicação do instituto em relevo.

Um conjunto normativo mais específico e cogente pode elevar a probabilidade de acerto da referida política pública, permitindo ao Estado o fortalecimento e a efetiva aplicação da doutrina do melhor interesse do adolescente e do jovem, no tocante ao acesso às oportunidades de profissionalização com vistas ao primeiro emprego, o que induz o desenvolvimento econômico e social e a fruição dos direitos fundamentais. 
Por fim, a pesquisa utiliza o método de abordagem indutivo e apresenta-se como exploratória quanto aos objetivos, de natureza qualitativa e com base nos procedimentos bibliográfico e documental. Não há estudos publicados na literatura indexada com a abordagem sugerida, o que destaca a originalidade em busca do norteamento de ações, tendo em conta a normatividade atual, e a proposta de melhorias no arcabouço jurídico.

\section{PRESERVAÇÃO DO EMPREGO EM TEMPOS DE PANDEMIA}

Os primeiros meses do ano de 2020 inauguraram um cenário que, para muitos, representa um verdadeiro caos social e institucional em face da pandemia decorrente da propagação da COVID-19. Apontase que o surgimento do vírus ocorreu em Wuhan, na China, tendo o primeiro caso oficial sido relatado em 12 de dezembro de 2019 (GRUBER, 2020), apresentando pacientes com quadro clínico de pneumonia grave.

Lima (2020) afirma que se trata de um vírus de rápida transmissão, que necessita de uma série de ações sanitárias; de combinação de tratamento médico, a depender do histórico do paciente; da aplicação de medidas de distanciamento ou isolamento social e de quarentena, para restrição de circulação de pessoas nos aglomerados urbanos e conter a disseminação.

Em aproximadamente dois meses, a doença espalhou-se pelo mundo (OPAS, 2020), o que resultou, em 11 de março, no reconhecimento pela Organização Mundial da Saúde (OMS) do estado de pandemia associado ao Coronavírus. Diante desse contexto, o Estado brasileiro realizou - sem critérios uniformes -, um conjunto de intervenções em diversas localidades do território nacional, com vistas à redução do potencial de contágio e letalidade. 
Em 6 de fevereiro de 2020, a Lei n. 13.979 fora publicada e passara a vigorar com a previsão de medidas para enfrentamento da emergência de saúde pública decorrente da pandemia da COVID-19, constando posteriormente nas Medidas Provisórias n. 927 (BRASIL, 2020b) e 936 (BRASIL, 2020c) um conjunto normativo destinado a empregados urbanos, rurais e domésticos, orientado, todavia, pela prevalência do acordo individual escrito sobre convenções e acordos coletivos, sob a justificativa de garantir a permanência do vínculo empregatício dentro dos contornos constitucionais (NOGUEIRA; FARIA, 2020), o que será discutido adiante.

Entretanto, tais ações não atingiram as proporções necessárias para impactar de modo substancial as estatísticas do país, gerando um prognóstico de extensão na duração das medidas restritivas. A título de exemplo, a Fundação de Vigilância em Saúde do Amazonas FVS/AM (2020) apontou que, até 23 de maio, haviam sido confirmados 28.802 casos e 1.744 óbitos (taxa de letalidade de 6\%) no estado apontado como um dos mais críticos, números que desconsideraram o índice de subnotificação e a reduzida quantidade de testes realizados.

Nesse contexto, surgem indagações quanto às medidas mais adequadas para conter a evolução descontrolada dos números de adoecimentos e mortes, o que passa inevitavelmente pela discussão a respeito das atividades essenciais que devem continuar em funcionamento, bem como das estratégias de preservação do emprego e da renda.

As mudanças foram repentinas e demandaram a edição de atos normativos nas mais variadas esferas, que abrangeram medidas provisórias, decretos, portarias e instruções normativas. De acordo com levantamento documental realizado no site do Planalto, com o tema específico "COVID-19", registra-se em 3 de fevereiro a primeira portaria tratando de estado de emergência, e a quantidade de atos multiplica-se enquanto persiste o estado de calamidade, com previsão de término em 31 de dezembro de 2020, conforme o Decreto Legislativo 6, de 20 de março de 2020. 
O cenário de crise enseja o enfrentamento da situação excepcional e sem precedentes, que demanda a adaptação de normas jurídicas, além da edição de medidas provisórias voltadas à regulação das relações jurídicas. Quanto ao Direito do Trabalho, as medidas abrangem contornos definidos em leis, medidas provisórias e decretos presidenciais, com destaque para a Lei n. 13.979/2020 - medidas para enfrentamento -, o Decreto 10.282/2020 - regulamenta a Lei n. 13.979 (BRASIL, 2020a) e define os serviços e atividades essenciais e as Medidas Provisórias n. 927 (BRASIL, 2020b) e 936 (BRASIL, 2020c) - medidas para a preservação do emprego e da renda.

Em 22 de março de 2020, editou-se a Medida Provisória n. 927 (BRASIL, 2020b), no dia seguinte alterada pela Medida Provisória n. 928, que promoveu a revogação do polêmico artigo 18 , que previa a suspensão contratual por até quatro meses sem obrigatoriedade de prestação pecuniária patronal ou estatal. O clima de insegurança jurídica ocasionado pela demora na edição de medidas adequadas ao enfrentamento da questão amenizou-se com a edição da MP n. 936 (BRASIL, 2020c), em $1^{\circ}$ de abril de 2020, que previu o pagamento de benefício emergencial vinculado à suspensão contratual ou à redução proporcional de jornada e salário.

Ressalta-se que o estudo analisa esse instrumento provisório, desde o ingresso no ordenamento pátrio até o respectivo término de vigência. Considerando que os dispositivos estudados foram incorporados pela Lei n. 14.020, de 6 de julho de 2020, as menções ao conteúdo dos artigos dirigem-se a este novel documento normativo. Sendo assim, não obstante a lei de conversão tenha sido editada depois de três meses da edição da medida provisória em questão, a confirmação do teor dos dispositivos da norma permite considerar válidas todas as ações promovidas no período de vigência e em consonância com a MP n. 936 (BRASIL, 2020c).

Encontra-se, pois, integralmente aplicável e surte efeitos em todas as relações laborais estabelecidas entre empregador e empregado, gênero que inclui, de acordo com o escopo do presente 
estudo e o artigo 443 da CLT (BRASIL, 1943), os contratos a tempo determinado (a exemplo da aprendizagem profissional), indeterminado (aplicável às pessoas a partir de dezesseis anos de idade) e intermitente (prestação de serviço subordinado em períodos descontínuos, conforme a demanda patronal e a concordância do trabalhador).

O custeio dessa parcela pelos cofres públicos possui como objetivo evitar o desemprego e manter os postos de trabalho durante a crise, por meio de mecanismos que garantam a continuidade das atividades empresariais e laborais, tendo como contrapartida a garantia no emprego pelo tempo equivalente ao utilizado pelo empregador como redução de jornada e salário ou suspensão contratual, contado do encerramento da validade de tais medidas. Como ressaltam Barros e Albuquerque (2020), a assunção estatal de parte das despesas pretende reduzir o impacto social decorrente do estado de calamidade pública.

Para o atual momento e dentro do escopo em que aplicáveis, as medidas provisórias atendem aos requisitos do artigo 62 da Constituição da República de 1988 (CR/88), que permite ao Presidente da República, em caso de relevância e urgência, a adoção de medidas provisórias, com força de lei, dentro do prazo de vigência temporário de sessenta dias, prorrogável uma vez por igual período, e imediatamente submetidas ao Congresso Nacional.

Pois bem, a MP n. 927 (BRASIL, 2020b) apresentou condições para enfrentamento dos efeitos econômicos decorrentes do estado de calamidade pública e para preservação do emprego e da renda. Dentre as opções à disposição do empregador, constam alterações nas regras aplicáveis ao teletrabalho, à antecipação de férias, ao aproveitamento de feriados, à utilização do banco de horas, às exigências administrativas em termos de segurança e saúde no trabalho, e ao recolhimento do Fundo de Garantia do Tempo de Serviço.

Ressalta-se que o presente estudo veicula ponderações referentes à duração da MP n. 927 (BRASIL, 2020b) limitadamente ao 
período de 22 de março de 2020 a 19 de julho de 2020, quando fora alcançada pelo instituto da caducidade e, portanto, deixou de vigorar. Nesse tocante, os mecanismos previstos por essa medida provisória devem ser lidos e compreendidos conforme a temporalidade em que utilizados e aplicados, em virtude do encerramento da validade.

Embora o objeto de avaliação consista nos impactos das medidas contidas nesse ato normativo, com atenção aos efeitos decorrentes do término do prazo de validade, a impossibilidade de utilização das alterações legislativas então promovidas em momento posterior não prejudica o uso durante o tempo em que compôs o ordenamento jurídico pátrio.

A perda da eficácia da MP 927 em 19 de julho de 2020 ocorre em virtude do conteúdo dos $\S \S 3^{\circ}$ e 11 do artigo 62 da Constituição da República (BRASIL, 1988), de modo que o Congresso Nacional deveria editar, no prazo de sessenta dias, um decreto legislativo para disciplinar a relações jurídicas decorrentes daquela legislação temporária. Ocorre que esse lapso temporal transcorreu sem que houvesse a edição desse instrumento normativo, o que gera a aplicabilidade do $\S 11$ do artigo 62 da Constituição (BRASIL, 1988), segundo o qual "as relações jurídicas constituídas e decorrentes de atos praticados durante sua vigência conservar-se-ão por ela regidas”.

Logo, permanecem válidos todos os acordos celebrados durante a vigência da MP n. 927 (BRASIL, 202ob). Sendo assim, entre 22 de março de 2020 e 19 de julho de 2020, as decisões tomadas no âmbito das relações laborais alcançadas por esse instrumento normativo estão juridicamente resguardadas, desde que não ultrapassem a data limite, consistente no término do reconhecimento do estado de calamidade pública, em 31 de dezembro de 2020, tal como prevê o seu artigo $1^{\circ}$. Enfim, os novos acordos devem observância às disposições da CLT (BRASIL, 1943).

Devem, no entanto, ser considerados os impactos nas relações sociais laborais e ponderado se os ajustes normativos não configuram ofensa desmedida à essência do Direito do Trabalho. É o caso da 
questionada possibilidade de antecipação de férias (desvirtuamento da finalidade de descanso e recomposição física e mental) e postergação do prazo de pagamento da remuneração em si (quinto dia útil do mês subsequente ao início do gozo) e do adicional de um terço (limite para a quitação da gratificação natalina - 20 de dezembro, portanto), como alertam Souza Junior et al. (2020), quanto aos artigos $8^{\circ}$ e $9^{\circ}$ da Medida Provisória n. 927 (BRASIL, 202ob).

Com efeito, a proposta de adoção do teletrabalho converge para a redução da estatística de adoecimentos e mortes relacionadas ao vírus - aplicável e indicado aos contratos de aprendizagem profissional -, não obstante a questionável regra de compartilhamento dos riscos do negócio contida no artigo 4, $\S 3^{\circ}$, da MP n. 927 (BRASIL, 2020b), mediante a previsão de contrato escrito entre as partes, firmado previamente ou no prazo de 30 dias da mudança do regime de trabalho, para a definição do reembolso de despesas e da responsabilidade pela aquisição, manutenção ou fornecimento dos equipamentos tecnológicos e da infraestrutura necessária e adequada.

No tocante à utilização do teletrabalho como alternativa de manutenção dos empregos no período da pandemia, Paixão e Schaefer (2020) alertam que a regulamentação do trabalho remoto pela legislação trabalhista não satisfez os anseios da classe trabalhadora, na medida em que mantidos os contornos da Lei n. 13.467/2017 (Reforma Trabalhista), que afastou o teletrabalho do controle de jornada e, por via de consequência, restringiu os empregados abrangidos por essa modalidade da percepção de horas extras, e endossou a possibilidade de utilização desse regime laboral como forma de aprofundamento da exploração.

A regulamentação do trabalho em tempos de pandemia seguiu a legitimação de práticas flexibilizatórias quanto à organização dos tempos de trabalho e de não trabalho, autorizando a ausência de controle quanto à jornada normal ou razoável, em prejuízo ao distanciamento entre a vida profissional e a vida pessoal dos teletrabalhadores, decorrente do direito fundamental ao lazer e à limitação da jornada, previstos no artigo $6^{\circ}$, caput, $7^{\circ}$, XII, e 217, $\S 3^{\circ}$, 
da CRFB (BRASIL, 1988). Em um cenário legislativo favorável às questões sociais, a eventual conversão das propostas em lei deveria desfazer os equívocos e implementar a necessária proteção ao meio ambiente laboral.

A suspensão de exigências administrativas em segurança e saúde no trabalho, prevista nos artigos 15 e 16 da MP n. 927 (BRASIL, 2020b), também se apresenta questionável, considerando a necessidade de maior vigilância no contexto atual. Não se pode interpretar como um possível relaxamento nas condições de trabalho, vez que o cenário de crise sanitária não só recomenda como impõe a atenção quanto aos treinamentos da equipe, ainda que por meios virtuais, em conformidade com as condições técnicas e pessoais dos empregados e a eficácia da atividade formativa (UCHÔA; UCHÔA, 2020)

Desse modo, a MP n. 927 (BRASIL, 2020b) ressalta condições precarizantes, impulsionando o dilema entre a perda o emprego - com pagamento integral ou reduzido de algumas verbas rescisórias, caso se caracterize a hipótese de força maior prevista no artigo 501 da CLT (BRASIL, 1943) - ou a manutenção dentro de uma perspectiva de regime jurídico inferiorizado.

Dentre outros fatores, a falta de conversão em lei decorreu da falta de consenso a respeito da possibilidade de as estratégias apresentadas incorporar definitivamente o ordenamento pátrio, tanto para futuras situações análogas - relacionadas ou não a um panorama de pandemia -, quanto para os contratos em geral, independentemente do contexto.

Ainda que aplicável durante o período em que esteve válida, entende-se que a norma não pode resultar em estipulação contratual de simples renúncia, abolição ou diminuição de direitos, especialmente no contexto de relações contratuais assimétricas, em que os contratantes não se encontram no mesmo plano - notadamente quanto à espécie contratual em estudo -, condição de desequilíbrio intensificada pela crise política, econômica e sanitária. 
Enfim, como ressaltam Ferreira, Koury e Oliveira (2020), contrariamente à exigência fática do momento de crise, em que as pessoas vulneráveis necessitam de proteção na formulação de políticas públicas voltadas à garantia do pleno emprego, renda justa e proteção previdenciária, os diplomas normativos destacados seguem agendas legislativas de viés neoliberal em detrimento dos direitos sociais, ao permitir a redução de salário e jornada, e a regulação por acordo individual entre partes que não gozam de igualdade material.

\section{DIREITO À PROFISSIONALIZAÇÃo E CONTRATO DE APRENDIZAGEM}

A aprendizagem profissional decorre do direito fundamental à profissionalização do adolescente e do jovem, e consiste em uma estratégia para a erradicação do trabalho infantil, características que empolgam a busca de soluções adequadas e aptas a proporcionar o acesso ao trabalho em condições protegidas, especialmente no contexto de crise causado pela pandemia da COVID-19 em que surgiram as citadas medidas provisórias.

Há previsão constitucional da aprendizagem a partir dos 14 anos de idade. Ademais, o Estatuto da Criança e do Adolescente - ECA (BRASIL, 1990) trata do direito à profissionalização e à proteção no trabalho, e prevê que as exigências pedagógicas relacionadas ao desenvolvimento pessoal e social prevalecem sobre o aspecto produtivo, bem como exige o respeito à condição peculiar de pessoa em desenvolvimento, tal como estabelecem o artigo $7^{\circ}$, XXXIII, da CRFB (BRASIL, 1988) e os artigos $6^{\circ}, 68$ e 69 da Lei 8.069 (BRASIL, 1990).

A seu turno, os artigos 428 a 433 da CLT (BRASIL, 1943) estabelecem os parâmetros relacionados ao contrato de aprendizagem, à obrigação de contratação do percentual de $5 \%$ a $15 \%$ (excluídas da 
base de cálculo as funções que não demandam formação profissional, tais como os cargos de nível técnico ou superior, gerência e chefia) por parte dos empregadores (opcional para microempresas e empresas de pequeno porte), às entidades qualificadoras, ao registro (estabelecimento ou entidades qualificadas em formação profissional), à jornada (seis horas, e, excepcionalmente oito horas, caso o jovem possua ensino fundamental e combine teoria e prática), à duração do contrato (por prazo determinado, até dois anos) e à idade do aprendiz (14 e 24 anos de idade, limite não aplicável aos aprendizes com deficiência).

Em nível infralegal, a contratação de aprendizes segue, sobretudo, as regras contidas no Decreto n. 9.579 (BRASIL, 2018a) e na Instrução Normativa n. 146 (BRASIL, 2018), sobre a formação técnico-profissional metódica e as atividades teóricas e práticas, organizadas em tarefas de complexidade progressiva, componentes dos programas de aprendizagem, e sobre a fiscalização laboral no âmbito de tais relações trabalhistas.

Em 2018, foram contratados 444.189 aprendizes em todo o país, quantidade 15\% superior à de 2017 (FNPETI, 2019), mas que reduziu nos anos de 2019 e 2020, mantendo-se por volta de $46 \%$ com idade inferior a dezoito anos. Em meados de dezembro de 2020, o país registrava $45 \%$ do cumprimento da cota de aprendizagem mínima do quantitativo total de 861.315 vagas, apenas 391.497 encontravamse preenchidas. Porém, existe espaço para o incremento desse quantitativo, que pode atingir aproximadamente 3 milhões de vagas, em caso de cumprimento do percentual máximo de $15 \%$ (AGÊNCIA SENADO, 2019).

O recorte da taxa de desocupação entre os jovens demonstra que, no primeiro trimestre de 2018, o desemprego no Brasil alcançou o então recorde histórico de 13,7\%, atingindo 14,1 milhões de pessoas, conforme o Instituto Brasileiro de Geografia e Estatística - IBGE (BENEDICTO, 2018). São 5,7 milhões de jovens entre 14 e 24 anos, e 
1,2 milhão de adolescentes entre 14 e 17 anos, faixa em que predominam as ocorrências de trabalho infantil.

Enquanto 40\% dos desempregados possuem idade compatível com a aprendizagem, a média de desemprego dos jovens entre 14 e 24 anos de idade representa o triplo da verificada na faixa de 25 a 59 anos de idade. Em 2016, estavam desempregados 27,2\% naquela faixa etária, contra 9,1\% nesta, segundo o Boletim Mercado de Trabalho divulgado pelo Instituto de Pesquisa Econômica Aplicada - IPEA (CAVALLINI e SILVEIRA, 2019).

A compreensão da aprendizagem como parte do processo educativo do jovem objetiva a melhoraria da qualificação profissional dos ingressantes no mercado formal e impacta as condições de vida dos núcleos familiares e das comunidades. Realiza-se na prática os ensinamentos apreendidos na escola e na fase teórica do programa, com as garantias legais. O investimento na formação de futuros profissionais viabiliza o exercício da responsabilidade social, contribuindo-se diretamente para a redução da pobreza e da desigualdade, além de servir de instrumento para o empregador moldar e dinamizar seu corpo funcional.

Segundo Mühlemann e Wolter (2014), a decisão de uma empresa pelo treinamento de aprendizes compreende a avaliação do binômio custo-benefício do investimento, em comparação com outras opções de garantia de trabalhadores qualificados, e a retenção dos aprendizes com melhor desempenho consiste em uma interessante estratégia de recrutamento.

A implantação do programa de aprendizagem nas empresas confere aos jovens a oportunidade de preparação para o mundo do trabalho por meio da formação teórico-prática, na qual são desenvolvidos conhecimentos e competências amplas, nos âmbitos pessoal, social e profissional. Presta, então, a importante missão de permitir a quebra do ciclo de exclusão social, favorecendo a qualificação profissional compatível com o estágio de desenvolvimento. 
Além disso, o contrato de aprendizagem contribui para a retenção na escola ou a volta aos estudos, ainda que na modalidade de Educação de Jovens e Adultos, para os que demonstram defasagem em razão da idade (GONÇALVES, 2014). Promove, ainda, o desenvolvimento físico, moral e psicológico; aumento das chances de permanência no mercado laboral; oferecimento de alternativa ao trabalho infantil; promoção da inclusão social dos jovens em situação de vulnerabilidade; e oferta de trabalhadores qualificados às empresas.

Clementino (2013) promove uma discussão sobre a importância da aprendizagem profissional como um instituto legal que reúne dois dos eixos basilares da política nacional para a juventude: educação e trabalho. Fonseca (2017) sintetiza que a aprendizagem profissional consiste em uma oportunidade de inserção de trabalhadores com deficiência no mundo do trabalho, que poderão aprender as tarefas na empresa. Afirma, ainda, que o direito à profissionalização assume relevância estratégica na chamada sociedade do conhecimento.

Se os avanços tecnológicos indicam que o modelo brasileiro de programa de aprendizagem profissional precisa se adaptar, o contexto da pandemia demanda ações de proteção e garantia de permanência dos contratos, para impedir que a primeira experiência no mercado laboral seja marcada por efeitos traumáticos vinculados à pandemia da COVID-19.

Concorda-se com a análise de Veloso (2019), no sentido de que a discussão de ações desenvolvidas precisa ser desenvolvida localmente, considerando as peculiaridades de cada região, com envolvimento das respectivas gestões públicas no planejamento e fomento da aprendizagem orientada pela emancipação da compulsoriedade e da precarização, e pela ampliação do alcance e da efetividade em termos de empregabilidade.

Todavia, discorda-se que a alternativa para a falta de Auditores Fiscais do Trabalho deva ser compensada com a divisão de responsabilidade quanto ao exercício do poder de polícia com agentes 
municipais ou estaduais. Na verdade, a defesa deve ser no sentido da reposição dos cargos vagos, que chegam a um terço do quadro, e da criação de ao menos mais 5 mil novos postos (IPEA, 2012), mediante a realização de concurso púbico para contratação desses agentes públicos que desempenham função estatal que vão além da exigência do cumprimento de cotas propriamente dita, pois zelam pela higidez das relações laborais.

A integralização do quadro de auditores pode beneficiar a fiscalização e o monitoramento e avaliação da eficácia dos programas de aprendizagem, a partir de ações como o estudo e acompanhamento sistematizados das trajetórias profissionais dos egressos, em relação aos jovens de condições semelhantes que não foram contemplados com a política, por falta de conhecimento ou oferta de oportunidade de contratação.

As autoridades locais e regionais podem e devem impulsionar as contratações e dialogar com os potenciais contratantes, as entidades qualificadoras e os agentes de fiscalização laboral, estruturados em coordenações e equipes regionais, que desempenham as ações de fiscalização dos contratos e programas de aprendizagem. No entanto, o caráter imperativo e nacional das normas trabalhistas demanda a reunião das atribuições de inspeção em órgão autônomo, livre de controle político, nos moldes da Convenção n. 81 da Organização Internacional do Trabalho (OIT).

\section{MEDIDAS APLICÁVEIS À APRENDIZAGEM PROFISSIONAL}

A OIT (2020) elaborou orientações básicas sobre a aplicação das disposições fundamentais das normas internacionais do trabalho pertinentes ao contexto do surgimento da COVID-19. Trata-se de uma compilação referente às questões mais frequentes no período de pandemia que, embora não aborde de modo exaustivo as medidas 
jurídicas ou políticas que poderiam ser adotadas, contém as possibilidades de enfrentamento inicialmente vislumbradas.

Dentre as sugestões, consta a indicação de que, em caso de suspensão, rescisão ou redução das garantias trabalhistas motivadas pelas repercussões econômicas da pandemia ou por motivos de segurança e saúde, deve-se permitir ao trabalhador a percepção de subsídios ou assistência em caso de desemprego involuntário, de acordo com a Convenção n. 168, sobre a Promoção do Emprego e Proteção contra o Desemprego, de 1988 (artigo 10), e a Convenção n. 102, sobre as Normas Mínimas de Seguridade Social, de 1952 (Parte IV).

Nesse sentido, os governos devem adotar medidas para ampliar as prestações de desemprego aos trabalhadores que enfrentam perda, suspensão ou redução de garantias, seja em caso de desemprego parcial, seja em razão de redução temporária de jornada ou suspensão do trabalho, situações contempladas incialmente na MP n. 936 (BRASIL, 2020c) e mantidas na Lei 14.020 (BRASIL, 2020a). Essas medidas de enfrentamento encontram respaldo nas orientações internacionais, não obstante mereçam críticas e ponderações a respeito da incidência e escopo de proteção.

Além de os instrumentos eleitos pelo Estado brasileiro terem resultado em perdas remuneratórias para uma parcela considerável de trabalhadores, esse conjunto de medidas restringiu-se ao primeiro ano da pandemia. Deixou-se de abranger o momento mais crítico até o momento (primeiro quadrimestre do ano de 2021), notadamente a segunda onda de casos e óbitos.

O agravamento da pandemia decorreu do insucesso e da desarticulação das ações de controle de circulação (em parte decorrente da exposição motivada pela necessidade de retorno ao trabalho, por falta de medidas de estímulo e compensação estatal que alcançassem as relações de emprego no ano de 2021) e da falta do adequado e tempestivo investimento em ações cientificamente comprovadas (vacinação e medidas de distanciamento social, para 
citar o mínimo), contexto que impulsionou o surgimento de novas variantes do vírus e o colapso nos sistemas de saúde observado nas diferentes regiões do país.

A seu turno, a Comissão Interamericana de Direitos Humanos (2020) divulgou uma resolução a respeito da proteção aos direitos humanos no contexto da COVID-19. Quanto aos grupos em situação de especial vulnerabilidade, o documento reforça que os Estados devem considerar as perspectivas interseccionais e atentar para as necessidades e o impacto diferenciado nos direitos humanos dos grupos historicamente excluídos ou em especial risco, referindo-se a crianças e adolescentes, aos trabalhadores e às pessoas em situação de pobreza.

Frisa-se que a proteção aos direitos da criança e do adolescente, especialmente no contexto laboral, fora reafirmada pela Corte Interamericana de Direitos Humanos na sentença de 15 de julho de 2020, referente ao Caso dos Empregados da Fábrica de Fogos de Santo Antônio de Jesus vs. Brasil, que destacou a exigibilidade dos artigos 19 e 26 da Convenção Americana de Direitos Humanos - CADH, associados à proteção contra o tratamento não isonômico, percebido na condição estrutural de desigualdade de natureza interseccional, em razão de diferentes esferas de violação incidentes sobre pessoas marcadas por fatores como a condição socioeconômica, local de residência, sexo biológico, cor da pele e idade.

Essa compreensão fora inaugurada no caso Lagos del Campo vs. Peru, em 2017, precedente que representou caráter paradigmático no tocante à justiciabilidade dos direitos econômicos, sociais e culturais, mediante o reconhecimento da autonomia da proteção ao direito do trabalho, a partir de uma nova interpretação e alcance normativo do conceito de progressividade no âmbito do Sistema Interamericano de Direitos Humanos (NASCIMENTO; CORREA; FERREIRA, 2020). Trata-se, então, de parâmetro normativo de direitos humanos vinculado ao conceito de justiça social, necessário às oportunidades de desenvolvimento das capacidades humanas (ANDRADE; MACHADO; CARVALHO, 2020). 
Nesse sentido, a Comissão entende serem descabidas ações de suspensão dos direitos da infância, do direito à vida, à integridade, à vedação do tratamento cruel ou degradante e à proteção da família. Reforça o dever de proteção, a partir da implementação de medidas que considerem as particularidades das pessoas em condição de desenvolvimento e que atendam seu interesse superior, o que abrange a garantia dos vínculos familiares e comunitários, da educação e de ações de prevenção ao contágio coerentes com as condições econômicas e sociais, pois os efeitos da pandemia são diferenciados em cada grupo populacional.

Tais ações devem considerar o fosso digital (MATTOS; CHAGAS, 2008), termo que remete a todo tipo de limitação ao acesso às novas tecnologias de comunicação e informação (internet, computadores, smartphones), por questões financeiras, intelectuais ou sociais. Desse modo, a Comissão recomenda aos Estados que utilizem meios para garantia do acesso à educação a todas as crianças e adolescentes, sem discriminação.

Quanto a esse ponto, estudantes universitários de cursos jurídicos relatam preferência pelo ensino presencial em relação ao remoto, em grande medida motivados pelas dificuldades de acesso aos recursos tecnológicos e estruturais necessários ao acompanhamento das atividades, que demandam a concessão de auxílio de universidades públicas nesse sentido (QUEIROZ; GOMES; TASSIGNY, 2020). São dificuldades que incidem de modo acentuado sobre os adolescentes e jovens contratados na qualidade de aprendizes.

Nesse contexto, a atuação articulada das coordenações regionais de fiscalização do trabalho aponta a obrigação legal de proteção dos trabalhadores com idade inferior a dezoito anos, rol que contempla os aprendizes nessa faixa etária. Esses trabalhadores devem ser protegidos em consideração à condição de seres humanos em desenvolvimento, garantindo-se a absoluta prioridade, a proteção integral e a observância de seu melhor interesse, tal como exige o artigo 227 da CRFB (BRASIL, 1988). 
O empregador detém o poder diretivo de ordenar e determinar as condições em que o adolescente prestará serviços. Em razão do dever objetivo de cuidado, possui a obrigação de adotar as medidas necessárias para a proteção integral, ainda que preventivamente, e de evitar ordens que exponham a situação de risco ou prejuízo à saúde. Torna-se, inicialmente, exigível o afastamento dos trabalhadores com idade inferior a dezoito anos de atividades que envolvam comparecimento pessoal, devido ao risco de contato com terceiros no trabalho, na entidade formadora e no deslocamento entre estes e sua residência.

A violação do dever de cuidado sujeita o empregador às penalidades administrativas, em virtude da proibição do trabalho a menores de dezesseis anos de idade - salvo a partir dos quatorze anos, na condição de aprendiz -, vedando-se aos menores de dezoito anos de idade o labor em locais prejudiciais à formação, ao desenvolvimento físico, psíquico, moral e social e em horários e locais que não permitam a frequência à escola, na forma do artigo 403 da CLT (BRASIL, 1943) e dos artigos $4^{\circ}$, parágrafo único, I, e 67, III, do ECA (BRASIL, 1990).

Logo, o manejo de medidas de proteção aos trabalhadores deve ser amplo e prioritariamente direcionado aos adolescentes, aprendizes ou não. Consiste em dever do empregador a adoção de medidas de proteção para os trabalhadores com idade inferior a dezoito anos, facultando-se a excepcional utilização de instrumentos da MP n. 927 (BRASIL, 2020b) - alteração para o regime de teletrabalho; antecipação de férias e antecipação de feriados - e da MP n. 936 (BRASIL, 2020c) - redução de jornada e salário; e suspensão temporária do contrato de trabalho.

Enquanto os mecanismos viabilizados pela MP n. 927 (BRASIL, 2020b) deixam de ser aplicáveis depois de 19 de julho de 2020, aqueles constantes na MP n. 936 (BRASIL, 2020c) foram reafirmados pela Lei 14.020 (BRASIL, 2020a), o que torna possível a utilização até 31 de dezembro de 2020, vez que o artigo $1^{\circ}$ desta lei indica a aplicação durante o estado de calamidade pública e da emergência de saúde pública de importância internacional decorrente do coronavírus. 
A alteração para o regime de teletrabalho pode ser comunicada e adotada independentemente da idade dos aprendizes, nos moldes dos artigos $4^{\circ}$ e $5^{\circ}$ da MP n. 927 (BRASIL, 202ob), e as entidades formadoras podem ministrar atividades teóricas remotamente, desde que a função do aprendiz seja compatível, o estabelecimento cumpridor da cota forneça a estrutura adequada e necessária, o desempenho das atividades seja acompanhado remotamente por instrutor e monitor e sejam observadas as especificidades do contrato, em especial os limites de jornada.

Por sua vez, a antecipação de férias pode ser utilizada, mesmo que os aprendizes não tenham completado o período aquisitivo, inclusive na forma de férias coletivas, nos termos do artigo $6^{\circ}$ da MP n. 927 (BRASIL, 2020b). Em tais hipóteses, as atividades teóricas e práticas devem ser interrompidas e a entidade formadora imediatamente comunicada. A antecipação de férias limita-se ao período que o aprendiz ainda teria direito até o fim do contrato e pode ser comprovada mediante a apresentação do aviso de férias contendo a ciência do trabalhador e a inserção do respectivo evento no eSocial.

Os empregadores poderão promover a antecipação de feriados quanto aos não religiosos (os demais dependem de acordo escrito) federais, estaduais, distritais e municipais, desde que notifiquem, por meio escrito ou eletrônico e com a antecedência mínima de 48 horas, os trabalhadores com idade inferior a 18 anos contemplados.

A seu turno, a redução proporcional de jornada e salário pode ser efetuada por acordo individual escrito nos percentuais de $25 \%$, $50 \%$ ou 70\%, preservado o salário-hora. Durante o período de redução da jornada, o aprendiz terá as atividades readequadas, conforme definido pelo empregador e pela entidade formadora, podendo optar pela execução somente das atividades teóricas ou práticas. Os percentuais de redução de jornada e salário podem ser alterados via negociação coletiva, mas o percentual inferior a $25 \%$ afasta o benefício, segundo o artigo 11, § 2 ${ }^{\circ}$, I, da Lei 14.020 (BRASIL, 2020a). 
A medida não pode ser adotada por mais de 180 dias, considerando as prorrogações promovidas pelo Decreto n. 10.422, de 13 de julho de 2020, e Decreto n. 10.470, de 24 de agosto de 2020, e persiste a obrigação de manter integralmente os benefícios concedidos pelo empregador anteriores à redução, tais como vale refeição, plano de saúde, plano odontológico e cesta básica, e o empregador pagará o salário na proporção da nova jornada, facultado o pagamento de ajuda compensatória, conforme consta no artigo $9^{\circ}, \S 1^{\circ}$, da Lei 14.020 (BRASIL, 2020a).

Por fim, a suspensão temporária do contrato de trabalho poderá ser adotada por até 180 dias contados da assinatura do acordo. Nesse período, veda-se a exigência de atividades teóricas e práticas, sob pena de descaracterização da medida e do pagamento imediato da remuneração e dos encargos sociais referentes a todo o período e a aplicação das penalidades previstas na legislação e das sanções previstas em convenção ou em acordo coletivo, nos moldes do artigo $8^{\circ}, \S 4^{\circ}$, da Lei 14.020 (BRASIL, 2020a).

O empregador que tiver auferido receita bruta superior a $\mathrm{R} \$ 4,8$ milhões em 2019 precisa arcar com a ajuda compensatória mensal de $30 \%$ do salário. O trabalhador fará jus aos benefícios concedidos pelo empregador anteriores à suspensão, exceto o vale transporte, pois não haverá deslocamento para o trabalho. Porém, a contagem do período para fins previdenciários depende do recolhimento na qualidade de segurado facultativo, regra aparentemente incompatível com o caráter protetivo dessa espécie contratual.

Tanto a redução proporcional de salário e jornada como a suspensão contratual geram garantia provisória de emprego, segundo a redação do artigo 10 da Lei 14.020 (BRASIL, 2020a), o que pode ocasionar a prorrogação do contrato. Em todo caso, necessita-se ao menos de acordo individual por escrito entre empregador e aprendiz, sendo a minuta encaminhada ao empregado com antecedência mínima de dois dias corridos para análise. Além disso, necessita-se de comunicação à entidade formadora e à entidade sindical profissional. Para viabilização do acesso ao benefício, o empregador ainda precisa 
comunicar a decisão ao Ministério da Economia, por meio da plataforma Empregador Web.

Em termos gerais, a medidas elencadas convergem para o intuito de preservação do emprego. Quando se trata de contratos de aprendizagem, as hipóteses de rescisão antecipada devem ser interpretadas de modo restritivo, especialmente porque tais garantias não foram atingidas pelas normas provisórias editadas. Sendo assim, os rompimentos contratuais antecipados dependerão da ocorrência de algum dos motivos previstos no artigo 433 da CLT (BRASIL, 1943), do encerramento definitivo das atividades do estabelecimento ou da rescisão indireta.

Enfim, os contratos cuja data de término recaia durante o período da pandemia podem ser rescindidos normalmente na data originalmente prevista, devendo a entidade formadora emitir o certificado de conclusão do programa referentes aos módulos concluídos. Logo, assegura-se a prorrogação do contrato para respeito à garantia provisória no emprego aos aprendizes atingidos pela adoção das medidas de redução proporcional de jornada e salário ou de suspensão temporária do contrato.

As restrições do período da pandemia não afastam, porém, a exigência de atendimento à cota de aprendizes, nos casos de encerramento de contrato ou aumento do quadro funcional que signifique a manutenção de aprendizes em quantitativo inferior ao devido, especialmente considerando que as novas contratações podem ocorrer por meio de entidades qualificadoras que ofertarem a formação teórica remota, no modelo de ensino à distância (EAD).

O Ministério Público do Trabalho - MPT (2020a, 2020b) ressalta que o artigo $3^{\circ}$, "a", da Convenção 182 da OIT considera dentre as piores formas de trabalho infantil qualquer atividade que, por sua natureza ou pelas circunstâncias em que é executada, seja suscetível de prejudicar sua saúde, segurança e moral. No caso da COVID-19, os riscos são reconhecidos pela OMS e os sintomas podem levar ao óbito. Ademais, não há pesquisas consistentes acerca dos 
efeitos da doença e de eventuais impactos futuros na saúde dos seres humanos.

Adolescentes aparentemente saudáveis podem padecer de doenças crônicas e comorbidades desconhecidas, as quais podem torná-los mais suscetíveis às complicações, situação agravada pela recorrente condição de vulnerabilidade socioeconômica dentro do público atendido. Logo, com amparo no princípio da precaução, que visa a impedir o risco de perigo abstrato de afetação da saúde, deve-se evitar a exposição de adolescentes a riscos de contaminação, no ambiente e no deslocamento para o trabalho.

Como a circulação nos meios de transporte e a convivência no mesmo ambiente facilitam a propagação do vírus, necessita-se do afastamento da formação teórica e prática de aprendizes, estagiários e trabalhadores adolescentes que demande presença física, na forma do artigo $2^{\circ}$ do ECA (BRASIL, 1990), obrigação reforçada no estágio (Lei 11.788/2008) e na aprendizagem, pois são relações especiais de trabalho nas quais o caráter protetivo e pedagógico prepondera sobre o produtivo.

O órgão expressa que a pandemia caracteriza situação excepcional e motivo de força maior, e demanda a interrupção da prestação de serviços sem redução ou suspensão do pagamento da remuneração dos aprendizes e da bolsa de estágio, com base no princípio da proteção integral e na aplicação analógica do artigo $6^{\circ}$, § $3^{\circ}$, da Lei 8.213 (BRASIL, 1991).

Em síntese, a instituição defende como prioridade a interrupção das atividades laborais presenciais dos adolescentes empregados, estagiários e aprendizes, garantida a percepção da remuneração contratual. Como alternativa, indica o trabalho remoto ou teletrabalho e a concessão ou antecipação de férias individuais ou coletivas. Além disso, entende que a suspensão do contrato de trabalho e a redução proporcional da jornada de trabalho e salário são medidas excepcionais, que podem ser adotadas pela empresa para os aprendizes com mais de dezoito anos de idade, caso não seja possível a adoção das medidas menos restritivas. 
Não obstante corresponda a uma espécie de contrato por prazo determinado, a excepcionalidade do período admite que o empregador, com anuência da entidade formadora, celebre termo aditivo, prorrogando-se a data de término do contrato de aprendizagem, para repor a carga horária teórica ou prática não executada durante o período da pandemia. Todavia, o MPT ressalta que são nulos de pleno direito os atos praticados pelos empregadores com o objetivo de desvirtuar, impedir ou fraudar a aplicação dos preceitos contidos nas normas que regem as relações de trabalho, tal como a rescisão do contrato fora das hipóteses legais e a simulação da redução de jornada e da suspensão de contrato.

No âmbito da Justiça do Trabalho, há decisão judicial no âmbito da Seção Especializada do Tribunal Regional do Trabalho da $9^{\mathrm{a}}$ Região, em sede de Mandado de Segurança Cível oooo74775.2020.5.09.0000, impetrado pelo MPT contra ato praticado pelo juiz da $17^{\text {a }}$ Vara do Trabalho de Curitiba que, nos autos de Ação Civil Pública 0000310-21.2020.5.09.0651, rejeitou o pedido de tutela de urgência consistente na interrupção da prestação de serviços presenciais por adolescentes aprendizes em supermercado. Entendeuse que os adolescentes não pertencem ao grupo de risco e que a empresa adota medidas para evitar o contágio, mantendo-se em funcionamento por ser atividade essencial. Expressou-se, ainda, que o labor dos aprendizes transcende o caráter pedagógico e insere-se na dinâmica empresarial.

Por sua vez, a decisão de segundo grau reconheceu que, dentro dos estabelecimentos autorizados a funcionar, há serviços não essenciais cuja prática presencial deve ser dispensada e que o trabalho desenvolvido pelos aprendizes não pode ser qualificado como essencial, por ser um contrato especial que assegura a formação técnico-profissional metódica e não pode substituir a mão de obra comum. Protege-se o adolescente, tendo a legislação proibido o labor em atividades insalubres, perigosas, em horário noturno, segundo preveem os artigos 424 e 428 da CLT (BRASIL, 1943). Ademais, esse 
público não compõe o grupo de risco, mas não é imune e transmite o vírus.

Considerando tais diretrizes, o deferimento da liminar contemplou a determinação da interrupção imediata das atividades práticas presenciais dos aprendizes menores de dezoito anos de idade, sem prejuízo da remuneração integral, enquanto perdurarem as medidas e recomendações de isolamento ou distanciamento social emanadas pelas autoridades e órgãos competentes, bem como a vedação da rescisão dos contratos de aprendizagem, salvo nas hipóteses legais. Quanto aos aprendizes em atividade administrativa, o empregador pode optar pelo trabalho remoto, arcando com os custos inerentes. A decisão fora integrada para contemplar as medidas permitidas pela MP n. 936 (BRASIL, 2020c) e reafirmadas pela Lei 14.020 (BRASIL, 2020a).

\section{ALTERnATIVAS DE PRESERVAÇÃO DO TRABALHO DO ADOLESCENTE}

Diante das manifestações da fiscalização laboral, do órgão ministerial e da magistratura trabalhista, nota-se a defesa do padrão protetivo inerente ao contrato de aprendizagem como espécie peculiar de emprego, no qual o interesse pela qualificação prepondera sobre o aspecto produtivo.

As condutas estipuladas encontram-se coerentes, mas algumas observações são necessárias. Compreende-se que as alternativas se alinham à proteção dos empregos em geral e, de modo específico, contribuem para a manutenção dos contratos de aprendizagem. São medidas passíveis de utilização pelos empregadores para superação do momento de dificuldade ocasionado pela pandemia, com impactos presentes e futuros, que agregam proteção diferenciada aos aprendizes, sejam adolescentes ou jovens, por alguns motivos.

Primeiramente, a suspensão contratual combinada com o ajuste do calendário do programa de aprendizagem pode permitir ao 
aprendiz a redução dos prejuízos em termos de formação profissional prática e teórica, em patamar superior à experimentada pela simples interrupção do contrato com a continuidade do pagamento integral da remuneração no período em que vigorar a restrição de aglomerações, nos casos em que o teletrabalho não for cabível.

Por sua vez, a suspensão contratual e a redução proporcional de jornada e salário apresentam vantagens para além da garantia de emprego. Quanto à remuneração, o cálculo beneficia uma expressiva quantidade dos contratos de aprendizagem, pois o benefício emergencial será calculado sobre a base mensal do salário-mínimo nacional, tal como esclarecem o artigo $6^{\circ}$ da Lei n. 14.020 (BRASIL, 2020a) e o artigo $5^{\circ}$ da Portaria 10.486 (BRASIL, 2020d), da Secretaria de Trabalho. Com efeito, trata-se de montante superior ao padrão remuneratório médio dos aprendizes em jornadas de quatro a seis horas diárias.

Na prática, a suspensão gera ao adolescente ou jovem que percebe meio salário-mínimo mensal - pagamento proporcional à jornada de quatro horas diárias - o acréscimo monetário de 70\% a $100 \%$, somando-se a participação do empregador - quando exigível , com o benefício pago pela União. Sob as mesmas balizas, adotada a redução proporcional de jornada e salário de $25 \%$, $50 \%$ ou $70 \%$, ao conjunto remuneratório desse mesmo aprendiz haveria acréscimo salarial em percentual idêntico à redução, ou seja, não obstante a participação do empregador em termos salariais seja diminuído, o benefício emergencial devido pela União corresponde ao dobro da perda salarial experimentada no período.

As medidas em questão são excepcionais e temporárias, e eventual prejuízo momentâneo à formação do aprendiz compensa-se pelas garantias que delas advêm e pela possibilidade de tais estratégias viabilizarem a continuidade das atividades desempenhadas pelos empregadores e, por consequência, o prosseguimento dos contratos de aprendizagem com o máximo de aproveitamento possível por parte do 
adolescente ou do jovem, com vistas à eventual conversão do liame em contratação por prazo de indeterminado.

Entende-se que as alternativas aplicáveis aos contratos de aprendizagem alinham-se aos objetivos do trabalho digno, nos moldes estabelecidos pela OIT, notadamente quanto à existência do emprego e políticas de sustentação, à regulamentação dos direitos laborais e à proteção social como extensão da condição da ética no trabalho. Todavia, nos trilhos das últimas alterações substanciais na legislação laboral, falha no tocante ao diálogo social, prejudicado quanto ao afastamento da negociação coletiva na adoção de medidas restritivas de direitos laborais, não obstante preceito constitucional expresso.

O cenário da pandemia contraria a afirmação de que se mostra excessivo o caráter protetivo do Direito Trabalho, especialmente quando se mantém regras contrárias à literalidade do texto constitucional, como ocorre quanto ao afastamento da negociação coletiva. A flexibilização não resolve ou atenua problemas econômicos ou de desemprego. Ao contrário, transfere os riscos do empreendimento aos empregados, comportamento incoerente com a interpretação sistemática da Constituição, que confere aos direitos sociais previstos no artigo $7^{\circ}$ a hierarquia de cláusula pétrea.

A discrepância entre a condição individual do empregado em relação à composição organizada do empregador, que orienta o princípio laboral da proteção, indica a falta de condições concretas para a negociação individual, especialmente dentro de um panorama contrário à resistência obreira, na linha do que defendem Nogueira $\mathrm{e}$ Faria (2020). A negociação coletiva e a interveniência sindical obrigatória permitem o reequilíbrio de forças necessário na análise dos termos de eventual redução de jornada e salário ou suspensão contratual, principais medidas para manutenção dos contratos.

Nesse sentido, o fortalecimento da negociação coletiva converte-se em pauta prioritária, notadamente em virtude da ampliação das possibilidades de flexibilização e alegada modernização das relações trabalhistas, que, notadamente a partir da Reforma Trabalhista, agrava o desequilíbrio contratual em benefício da classe 
patronal e do sistema produtivo. Sob a justificativa de ganho de produtividade e de competitividade (FERRER; ALVES, 2018), olvidase o respeito à dignidade da parte hipossuficiente da relação.

As alterações implementadas desafiam a vedação ao retrocesso social, decorrente da leitura do caput do artigo $7^{\circ}$ do texto constitucional e do artigo 26 da $\mathrm{CADH}$, que vulnerabiliza as relações de trabalho no país, pois distanciam a proteção jurídica necessária ao avanço da perspectiva de cidadania plena (VALENTE; FOGAÇA; SILVA, 2018).

A abordagem genérica adotada pelas normas divulgadas no período da pandemia não contempla os contornos dos contratos de aprendizagem profissional, do estágio e do trabalho de adolescentes. Não há uma normativa específica e adequada a tais realidades, na medida em que os principais instrumentos estudados limitam-se a mencionar que os seus termos alcançam os contratos de aprendizagem profissional - artigo 15 da Lei 14.020 (BRASIL, 2020a) - ou que se permite a adoção do regime de teletrabalho, trabalho remoto ou trabalho a distância para estagiários e aprendizes - artigo $5^{\circ}$ da MP n. 927 (BRASIL, 2020b) -, sem que exista um tratamento especialmente dedicado a esses sujeitos de direitos, nesta ou em outras normas que regulam as relações laborais no período da pandemia. A inexistência de instrumentos normativos voltados a tais realidades gera insegurança jurídica e comportamentos não uniformes.

Desse modo, como diretrizes sugeridas para os atos normativos referentes à realização presencial das atividades práticas relativas à aprendizagem profissional e aos adolescentes empregados ou estagiários, sugere-se que as decisões sejam diferenciadas a depender da natureza do vínculo e da idade, situações condensadas em dois grupos.

Quanto os aprendizes e estagiários com idade superior a dezoito anos, entende-se que podem exercer a atividade prática de acordo com a liberação de funcionamento por parte das autoridades locais. Por sua vez, no tocante aos aprendizes, empregados não 
aprendizes e estagiários com idade inferior a dezoito anos, defendese a utilização das estratégias ofertadas pela MP n. 927 (BRASIL, 2020b) - limitadamente ao período de vigência - e pela MP n. 936 (BRASIL, 2020c) - na forma da conversão na Lei 14.020 (BRASIL, 2020a) - ou usufruir de licença remunerada, e serem liberados das atividades práticas enquanto não retomada a normalidade das atividades escolares presenciais, como medida de proteção decorrente do dever objetivo de cuidado exigível do empregador e pela preponderância do caráter de formação sobre o aspecto produtivo.

Especificamente quanto à aprendizagem profissional, entende-se que a formação teórica deve ser interrompida ou convertida na modalidade à distância, com a garantia de estrutura e acesso por parte dos aprendizes, independentemente da idade, enquanto não houver liberação de retorno presencial por parte das autoridades locais.

Com efeito, além das determinações relativas a tais relações contratuais, a verificação da efetividade e o exercício do poder de polícia administrativa de natureza laboral dependem do necessário preenchimento do quadro da fiscalização do trabalho. Os últimos certames foram lançados em 2003, 2006, 2010 e 2013, período em que se observa a média de um concurso a cada três anos. Desde então, somam-se sete anos sem um novo edital, e os quadros diminuem a cada ano, sem perspectiva de concurso. Em 2018, restavam vagos 1.309 dos 3.640 cargos criados por lei (35,9\%), não obstante a necessidade de oito mil auditores para atendimento às diretrizes da Convenção 81 da OIT.

Por fim, revela-se a necessidade de estímulo à aprendizagem profissional como política pública de ingresso no mercado de trabalho, sobretudo no cenário de desemprego elevado, observado nos últimos anos e acentuado na pandemia. No período de 20 a 26 de setembro de 2020, a taxa de desocupação encontrava-se em 14,4\% e 15,3 milhões de pessoas não procuraram trabalho por conta da pandemia ou por falta de oferta (IBGE, 2020). 


\section{CONSIDERAÇÕES FINAIS}

As diferentes realidades nas regiões urbanas e rurais do país demandam que o conjunto de atos normativos seja coeso, preocupe-se com a segurança da coletividade e atente às peculiaridades do público a que se destinam, na medida em que envolve a articulação de aspectos socioeconômicos e jurídicos, em um contexto inédito no cenário mundial, em que a pandemia expõe a necessidade de fortalecimento do caráter protetivo do Direito do Trabalho.

Em especial, necessita-se com urgência de marcos legais para a proteção, promoção e adaptação do instituto da aprendizagem, de modo a fortalecer a principal política pública de voltada à facilitação do acesso ao mercado de trabalho. Mostra-se indispensável a divulgação de diretrizes e orientações padronizadas por parte das autoridades competentes, quanto ao momento e a forma adequada de retorno ao trabalho dos aprendizes adolescentes, estagiários e trabalhadores com idade inferior a dezoito anos, servindo de orientação aos governos locais.

Além disso, admitem-se avanços, como a ampliação da destinação de vagas a adolescentes em condições de vulnerabilidade, que atualmente se limita à modalidade alternativa de contratação, constante no artigo 66, $\S 5^{\circ}$, do Decreto 9.579 (BRASIL, 2018a), quando o empregador não possui estrutura ou as atividades não comportam a manutenção de todos os aprendizes e se permite a assinatura de termo de cooperação para que a parte prática seja desenvolvida em órgão públicos ou entidades sem fins lucrativos, contabilizando-se a cota para o contratante.

Entende-se que a função social do contrato e do trabalho seria mais eficaz se a regra sofresse ampliação, para contemplar toda e qualquer modalidade de contratação. A elaboração de instrumentos normativos nesse sentido pode contribuir para o aprimoramento do instituto, a partir da instituição de benefícios fiscais para estimular a 
contratação de adolescentes e jovens em tais condições e da admissão de aprendizes pela administração pública direta, por meio de contratos de prestação de serviços ou convênios com entidades sem fins lucrativos.

Também se vislumbra o fomento da aprendizagem via EAD, notadamente nas localidades com menor quantidade de empresas obrigadas a contratar. A limitação vinculada ao déficit de inclusão digital nas diferentes regiões brasileiras tem motivado a ação integrada entre Secretaria de Inspeção do Trabalho, Defensoria Pública da União, Ministério Público do Trabalho e Agência Nacional de Telecomunicações para a busca soluções para que os empregados aprendizes tenham assegurado o acesso ao conteúdo on-line dos cursos.

A pandemia expõe a dificuldade de acesso aos meios tecnológicos, quadro que exige a promoção de ações interministeriais e interinstitucionais, para propiciar a continuidade dessa importante política pública adequada à nova realidade. As entidades qualificadoras igualmente precisam de estímulo quanto à capacitação periódica e continuada dos profissionais contratados, em virtude das mudanças no processo de profissionalização em tempos de restrição de locomoção e de aglomeração em salas de aula e nos locais de trabalho.

Portanto, consistindo o trabalho na principal forma de inserção social e de concretização da dignidade, justiça social e cidadania, as alterações normativas não devem acarretar a retirada de direitos e o esvaziamento de garantias. Pelo contrário, precisam orientar-se no sentido de evitar a afronta a tais garantias consolidadas e impulsionar melhorias à parte hipossuficiente. 
Preservação Dos Contratos De Aprendizagem Profissional Em Tempos De...

Data de Submissão: 04/07/2020

Data de Aprovação: 15/04/2021

Processo de Avaliação: double blind peer review

Editor Geral: Jailton Macena de Araújo

Editor de Área: Alana Ramos Araújo

Assistente Editorial: Stephany Yohanne Rolim Pereira

\section{REFERÊNCIAS}

AGÊNCIA SENADO. Aprendizagem profissional é subutilizada no Brasil, afirmam especialistas. 19 mar. 2019.

Disponível em:

https://www12.senado.leg.br/noticias/especiais/especialcidadania/aprendizagem-e-subutilizada-no-brasil-afirmamespecialistas. Acesso em: 4 jul. 2020.

ANDRADE, Denise Almeida de; MACHADO, Monica Sapucaia; CARVALHO, Grasielle Borges Vieira de. 50 Anos Do Pacto De São José Da Costa Rica: Reflexões Sobre Justiça Social no Brasil. Prim@ Facie. João Pessoa, v. 18, n. 39, p. 01-31, 4 fev. 2020.

BARROS, Alessandra Almeida; ALBUQUERQUE, Larisse Leite. Os impactos jurídicos da COVID-19 no direito do trabalho e as medidas provisórias em tempos de calamidade pública: relativização da dignidade da pessoa humana? In: MELO, Ezilda; BORGES, Lize; SERAU JÚNIOR, Marco Aurélio (Org.). COVID-19 e direito brasileiro: mudanças e impactos. São Paulo: Tirant lo Blanch, p. 243-255, 2020.

BENEDICTO, Marcelo. Desemprego volta a crescer no primeiro trimestre de 2018. Agência IBGE. Estatísticas Sociais. 27 abr. 2018. Disponível em: https://agenciadenoticias.ibge.gov.br/agencianoticias/2012-agencia-de-noticias/noticias/20995-desempregovolta-a-crescer-no-primeiro-trimestre-de-2018. Acesso em 20 mar. 2020.

BRASIL. Constituição da República Federativa do Brasil de 1988. Brasília, DF: Presidência da República, 1988. Disponível em: http://www.planalto.gov.br/ccivil_03/Constituicao/

Constituiçao.htm. Acesso em: 2 jun. 2020.

BRASIL. Decreto-Lei n. 5.442, de $1^{\circ}$ de maio de 1943. Consolidação das Leis do Trabalho. 1943. Disponível em: http://www.planalto.gov.br/ccivil_03/DecretoLei/Del5452compilado.htm. Acesso em: 4. jun. 2020. 
BRASIL. Decreto n. 9.579, de 22 de novembro de 2018. Consolida atos normativos editados pelo Poder Executivo federal que dispõem sobre o aprendiz e dá outras providências. 2018a. Disponível em: http://www.planalto.gov.br/ccivil_03/_Ato20152018/2018/Decreto/D9579.htm. Acesso em 14 jun. 2020.

BRASIL. Instrução Normativa n. 146, de 25 de julho de 2018. Dispõe sobre a fiscalização do cumprimento das normas relativas à aprendizagem profissional. $2018 \mathrm{~b}$. Disponível em: https://www.in.gov.br/materia/-

/asset_publisher/KujrwoTZC2Mb/content/id/34730621/do1-2018o7-31-instrucao-normativa-n-146-de-25-de-julho-de-2018-

34730599. Acesso em: 13 jun. 2020.

BRASIL. Lei n. 8.069, de 13 de julho de 1990. Dispõe sobre o Estatuto da Criança e do Adolescente e dá outras providências. 1990. Disponível em:

http://www.planalto.gov.br/ccivil_o3/leis/18069.htm. Acesso em 28 jun. 2020.

BRASIL. Lei n. 8.213, de 24 de julho de 1991. Dispõe sobre os Planos de Benefícios da Previdência Social e dá outras providências. 1991. Disponível em:

http://www.planalto.gov.br/ccivil_o3/leis/18213cons.htm. Acesso em 4 jun. 2020.

BRASIL. Lei n. 14.020, de 6 de julho de 2020. Institui o Programa Emergencial de Manutenção do Emprego e da Renda e dispõe sobre medidas trabalhistas complementares para enfrentamento do estado de calamidade pública e dá outras providências. 2020a. Disponível em:

http://www.planalto.gov.br/ccivil_03/_ato2019-

2022/2020/Lei/L14020.htm. Acesso em 29 dez. 2020.

BRASIL. Medida Provisória n. 927, de 22 de março de 2020. Dispõe sobre as medidas trabalhistas para enfrentamento do estado de calamidade pública e dá outras providências. 2020b. Disponível em:

http://www.planalto.gov.br/ccivil_03/_ato2019-

2022/2020/Mpv/mpv927.htm. Acesso em 14 abr. 2020.

BRASIL. Medida Provisória n. 936, de $1^{\circ}$ de abril de 2020. Institui o Programa Emergencial de Manutenção do Emprego e da Renda e dispõe sobre medidas trabalhistas complementares para enfrentamento do estado de calamidade pública e dá outras providências. $2020 c$. Disponível em: http://www.planalto.gov.br/ccivil_03/_ato20192022/2020/mpv/mpv936.htm. Acesso em 25 abr. 2020.

BRASIL. Portaria n. 10.486, de 22 de abril de 2020, da Secretaria de Trabalho. Edita normas relativas ao processamento e 
Preservação Dos Contratos De Aprendizagem Profissional Em Tempos De...

pagamento do Benefício Emergencial de que trata a Medida Provisória $n^{\circ}$ 936, de $1^{\circ}$ de abril de 2020. 2020d. Disponível em: https://www.in.gov.br/en/web/dou/-/portaria-n-10.486-de-22de-abril-de-2020-253754485. Acesso em 14 jun. 2020.

CAVALLINI, Marta; SILVEIRA, Daniel. Desemprego é o maior em 7 anos em 13 capitais do país, diz IBGE. G1 - Economia. 22 fev. 2019. Disponível em:

https://g1.globo.com/economia/noticia/2019/o2/22/desempregocai-em-6-das-27-unidades-da-federacao-no-40-tri.ghtml. Acesso em 12 mar. 2020.

CLEMENTINO, Josbertini Virginio. Aprendizagem Profissional: a lei que promove o trabalho descente para juventude e desenvolvimento econômico e social no Brasil. IPEA, Brasília, v. 55, p. 45-50, 2013.

COMISSÃO INTERAMERICANA DE DIREITOS HUMANOS. Resolución 1/2020. Pandemia y Derechos Humanos en las Américas. Disponível em: https://www.oas.org/es/cidh/decisiones/pdf/Resolucion-1-20es.pdf. Acesso em 2 abr. 2020.

FERREIRA, Otávio Bruno da Silva; KOURY, Suzy Elizabeth Cavalcante; OLIVEIRA, Felipe Guimarães de. O mundo do trabalho em tempos de pandemia no Brasil: o incremento da precarização da força laboral.Prim@ Facie, v. 19, n. 42, p. 37-85, 16 out. 2020.

FERRER, Walkiria Martinez Heinrich; ALVES, Giovanni. Flexibilização trabalhista e o empresariado brasileiro: alguns apontamentos. Prim@ Facie. João Pessoa, v. 17, n. 35, p. 77-107, 2018.

FONSECA, Ricardo Tadeu Marques da. As formas de aprendizagem no Brasil: questões emergentes. In: Aprendizagem profissional e direitos humanos o direito fundamental dos jovens à profissionalização. Mariane Josviak, Regina BergamaschiBley e Silvia Cristina Trauczynski (Org.). São Paulo: LTr, p. 15-29, 2017.

Fórum Nacional de Prevenção e Erradicação do Trabalho Infantil FNPETI. Mais de 440 mil aprendizes foram contratados em todo o país no ano passado. 27 mar. 2019. Disponível em: https://fnpeti.org.br/noticias/2019/03/27/mais-de-440-milaprendizes-foram-contratados-em-todo-o-pais-no-ano-passado/. Acesso em 14 jun. 2020.

FUNDAÇÃO DE VIGILÂNCIA EM SAÚDE DO AMAZONAS FVS/AM. Monitoramento da COVID-19 no estado do Amazonas. Disponível em: http://www.saude.am.gov.br/painel/corona/. Acesso em 24 mai. 2020. 
GONÇALVES, Ana Lucia de Alencastro. Aprendizagem profissional: trabalho e desenvolvimento social e econômico. Estudos avançados. São Paulo, v. 28, n. 81, p. 191-200, 2014.

GRUBER, Arthur. COVID-19: o que se sabe sobre a origem da doença. Jornal da USP. 14 abr. 2020. Disponível em: https://jornal.usp.br/artigos/covid2-o-que-se-sabe-sobre-a-origemda-doenca/. Acesso em 12 mai. 2020.

INSTITUTO DE PESQUISA ECONÔMICA APLICADA - IPEA. Nota Técnica $n^{\circ}$ 4. A necessidade de auditores fiscais do Trabalho no Brasil: uma análise contemplando o grau de descumprimento da legislação trabalhista. Jul. 2012. Disponível em: https://www.ipea.gov.br/portal/images/stories/PDFs/nota_tecnica/ 120731_nt_04_disoc.pdf. Acesso em 31 mai. 2020.

INSTITUTO BRASILEIRO DE GEOGRAFIA E ESTATÍSTICA IBGE. Desocupação, renda, afastamentos, trabalho remoto e outros efeitos da pandemia no trabalho. Disponível em: https://covid19.ibge.gov.br/pnad-covid/trabalho.php. Acesso em 29 dez. 2020.

MATTOS, Fernando Augusto Mansor de; CHAGAS, Gleison José do Nascimento. Desafios para a inclusão digital no Brasil. Perspectivas em Ciência da Informação. Belo Horizonte, v. 13, n. 1, p. 67-94, abr. 2008.

MINISTÉRIO PÚBLICO DO TRABALHO. Procuradoria-Geral do Trabalho e Coordenadoria Nacional de Combate à Exploração do Trabalho da Criança e do Adolescente. Nota Técnica Conjunta 05 de 2020. 18 mar. 2020. Dispõe sobre a defesa da saúde dos trabalhadores, empregados, aprendizes e estagiários. Disponível em: https://mpt.mp.br/pgt/noticias/notatecnica_adolescentes.pdf. Acesso em 7 mai. 2020.

MINISTÉRIO PÚBLICO DO TRABALHO. Procuradoria-Geral do Trabalho e Coordenadoria Nacional de Combate à Exploração do Trabalho da Criança e do Adolescente. Nota Técnica Conjunta 10 de 2020. 26 abr. 2020. Dispõe sobre empregados e aprendizes no contexto da MP 936 de 2020 . Disponível em: https://mpt.mp.br/pgt/noticias/nota-tecnica_n-1020_coordinfancia-1.pdf. Acesso em 7 mai. 2020.

MÜHLEMANN, Samuel; WOLTER, Stefan. Return on investment of apprenticeship systems for enterprises: Evidence from costbenefit analyses. In: IZA Journal of Labor Policy, n. 3, 2014. Disponível em: http://www.izajolp.com/content/3/1/25. Acesso em 11 mar. 2020. 
Preservação Dos Contratos De Aprendizagem Profissional Em Tempos De...

NASCIMENTO, Laura Fernanda Melo; CORREA, Igo Zany Nunes; FERREIRA, Adriano Fernandes. Caso Lagos del Campo vs. Peru e seu duplo papel paradigmático na evolução da justiciabilidade de direitos sociais perante a Corte Interamericana de Direitos Humanos.

Prim@ Facie, v. 18, n. 39, p. 01-31, 30 jan. 2020.

NOGUEIRA, Bernardo Gomes Barbosa; FARIA, Fernanda Nigri. Direito do trabalho em tempos de pandemia de COVID-19. In: MELO, Ezilda; BORGES, Lize; SERAU JÚNIOR, Marco Aurélio (Org.). COVID-19 e direito brasileiro: mudanças e impactos. São Paulo: Tirant lo Blanch, p. 226-242, 2020.

ORGANIZAÇÃO INTERNACIONAL DO TRABALHO - OIT. Las normas de la OIT y el COVID-19 (coronavirus) - versión 2.1. 29. mai. 2020. Disponível em:

https://www.ilo.org/global/standards/WCMS_739939/lang-es/index.htm. Acesso em 31 mai. 2020.

PAIXÃO, Tamiris Vilas Bôas da; SCHAEFER, Matheus Karl Schmidt. COVID-19 e teletrabalho: uma análise dos tempos de trabalho e de não trabalho. In: MELO, Ezilda; BORGES, Lize; SERAU JÚNIOR, Marco Aurélio (Org.). COVID-19 e direito brasileiro: mudanças e impactos. São Paulo: Tirant lo Blanch, p. 278-298, 2020.

QUEIROZ, Daiane; GOMES, Ana Carolina Neiva Gondim Ferreira; TASSIGNY, Mônica Mota. Aulas remotas e ensino a distância no período pós-pandemia: um olhar sobre o ensino jurídico pela perspectiva dos universitários em fortaleza.Prim@ Facie, v. 19, n. 42, p. 402-429, 16 set. 2020.

SOUZA JUNIOR, Antonio Humberto de et.al. Medida Provisória n. 927/2020: comentada artigo por artigo. São Paulo: Revista dos Tribunais, 2020.

UCHÔA, Silvia Beatriz Beger. UCHÔA, Bruno Beger. Coronavírus (COVID-19) - Um Exame Constitucional e Ético das Medidas Previstas na Lei n. 13.979, de 6 de fevereiro de 2020. Cadernos de Prospecção. Salvador, v. 13, n. 2, Edição Especial, p. 441-458, 2020.

VALENTE, Nara Luiza; FOGAÇA, Vitor Hugo Bueno; SILVA, Silmara Carneiro e. A reforma trabalhista brasileira e retrocessos na garantia de direitos fundamentais do trabalhador.Prim@ Facie, v. 17, n. 35, p. 01-32, 25 set. 2018.

VELOSO, José Rodrigo Paprotzki. Aprendizagem Profissional e o poder público municipal: proposta de maior eficácia à política pública. Revista Brasileira de Políticas Públicas. Brasília, v. 9, n. 1, p. 206-227, 2019. 


\title{
Preservation Of Professional Learning Contracts In Times Of Pandemic By Covid-19
}

\author{
Emerson Victor Hugo Costa de Sá
}

\author{
Anderson Lincoln Vital da Silva
}

\author{
Valena Jacob Chaves Mesquita
}

\begin{abstract}
The paper analyzes the strategies for maintaining professional learning contracts in times of pandemic by COVID-19. Main public policy focused on the first job, the institute provides opportunities for methodical technical and professional training for adolescents and young people, in addition to being a strategy for the eradication of child labor. The public health crisis scenario, resulting from the new Coronavirus, generated recognition of the state of public calamity in March 2020, which caused instability in legal relations and the need for regulatory adaptation. In this context, the applicability of the legal instruments instituted during the health crisis arising from COVID-19 is analyzed, with special emphasis on the hermeneutic analysis of Provisional Measure 927, whose effects ceased with its expiry, and Law n. 14,020, of July 6, 2020, as a result of the conversion of Provisional Measure n. 936, notably regarding the preservation of the adolescent's work in the face of this new reality, through professional learning and qualification in times of pandemic. The research uses the method of inductive approach and presents itself as exploratory as to the objectives, of a qualitative nature and based on bibliographic and documentary procedures. It is concluded that the learning contracts were adjusted to make continuity feasible, but there is a need for more precise regulatory frameworks and attentive to the specificities of the institute, especially regarding the adolescent and the socially vulnerable public.
\end{abstract}

Keywords: COVID-19. Professional learning. Public policy.

DOI: https://doi.org/10.22478/ufpb.1678-2593.2021v20n43.53789

Conteúdo sob licença Creative Commons: Attribuition-NonCommercial-NoDerivative 4.o International (CC BY-NC-ND 4.0)

(cc) BY-NC-ND 